\title{
Petrol Engine Fault Detection Using Mechanical Vibration Analysis
}

\author{
Mohamed khairy ${ }^{1}$, Mohammed Abdo $^{2}$ and Sabry Allam ${ }^{3}$ \\ Ph.D. Scholar ${ }^{1}$, Assistance Professor ${ }^{2}$, Professor $^{3}$ \\ Automotive Technology Department \\ Faculty of Technology and Education \\ Helwan University \\ Cairo, Egypt
}

\begin{abstract}
Vibration monitoring is the most widely used condition monitoring technique, where the machine's vibrations are analyzed to determine incipient faults. The early detection of a fault has many advantages as detecting a simple fault before causes too complicated problems. Every machine contains mechanical parts that emit a vibration. These vibrations can be monitored and recorded as a reference signal, displaying it using different strategies such as the time domain, frequency domain, time-frequency domain simultaneously. The root mean square (RMS) method is used to analyze the signal to obtain the signal code.

This paper presents a monitoring method, displaying, analyzing and coding of the vibration signal using a newly invented device called Immediate Diagnosis Device (IDD) presented by the same authors to detect the Daewoo Lanos engine faults using a mobile device. A vibration sensor (model: 333B32) was installed on the engine body to monitor the engine vibrations at different engine speeds 900 and $1500 \mathrm{rpm}$. The measured signal is fed to IDD and passes through a series of operations and processing in its components to assess the engine fault. Through IDD, the vibration signals were sent to the processing unit microcontroller 32BIT72MHZ-12BIT ADC, Serial Interface (STM32F103C8T6) to store and process it. Then compares it with the reference data by using Microsoft Visual Studio and the $C++$ language program, the final result will be displayed a message on the device screen LCD (16X2 8BIT) to explain the fault reason.
\end{abstract}

Keywords: Petrol Engine, Vibration Analysis, Fault Detection, Immediate Diagnosis Device.

\section{INTRODUCTION}

Today condition monitoring using vibration analysis isn't only used for easy proposes like bearings and gears fault detection but is also utilized in hybrid motors and cars within the industry for detecting or anticipating faults [1]. Fault detection via vibration analysis is one of modern methods which have many uses in car industry. In recent years lots of investigations of vibrational behaviour monitoring were done by means of researchers to detect and fix possible faults in various industries in rotating machines like vehicles engines [2] [3].Current vehicle maintenance strategies generally consist of corrective and preventive maintenance approaches or a combination of these. In the corrective maintenance approach, the vehicle is maintained on an "asneeded" basis, i.e. after a fault has occurred. This can be a risky approach as it may, over time, lead to unexpected breakdowns and more costly repairs due to higher levels of damage. At the other extreme, preventive maintenance relies on replacing components and fluids based on a conservative schedule to "prevent" possible failures. Although preventive maintenance programs may increase system availability, they lead to increased cost of vehicle ownership due to the replacement of parts and fluids well before the end of their operating life [4]. Fault diagnosis and condition monitoring is a valuable set of methods designed to ensure that the engine stays in good condition during its lifecycle [5] [6]. Acoustic Emission (AE) signal and Vibration are the foundations of many condition monitoring methods. Status Monitor can save money by Increasing maintenance efficiency by reducing the risk of critical accidents and preventing breakdowns. Early detection of defects and diagnostics not only provide information about the nature of the problem but also allow maintenance personnel to plan for what is needed corrective action. Thus, operating losses can be minimized in lower labour, spare parts cost, less downtime, and more efficient use of Maintenance resources [7] [8]. The continuing push to develop engine monitoring systems that can both monitor operating performance, and provide effective fault diagnostics and prognostics has led to continuing research interest regarding the development of monitoring technologies. This interest has resulted in the continued development of engine monitoring methods 
using both established and emerging engine monitoring technologies. As an example, recent studies have investigated the automation, and improvement of the fault diagnosis task using tribology, cylinder pressure, and vibration data as well as thermodynamic modelling, acoustic recordings, instantaneous crank-angle velocity measurements and acoustic emission data [9] . To diagnosis different fault types, conventional techniques vibration-based fault diagnosis were focused on the amplitude difference in the time domain or frequency domain. For monitoring purposes, several signal types can be measured including rotational angle, temperature, speed, vibration, fuel quality, and oil quality [10]. Z.Geng and J.Chen [11] Developed a nonlinear model is to discuss the slap-induced vibration response to the piston-slap phenomenon inside the reciprocating engine and evaluated the slap-induced vibration response and its correlation with the inner-cylinder piston-slap impact using numerical integration procedure. The simulating results, by introducing a quick wavelet-packet decomposition and reconstruction algorithm, designed a special experiment is created to practically extract results. Comparison between the simulation and much measured and reconstructed engine vibration signals verifies the effectiveness and usefulness of this approach. A. Zabihi et al. [12] proposed a method based on discrete wavelet transform and energy spectrum. And presented a combustion fault detection technique using condition monitoring for a 12-cylinder diesel engine based on vibration signature analysis and using artificial neural network fast Fourier transform (FFT), discrete wavelet transforms. The experimental results verified that vibration signals acquired from the intake manifold have more potential in fault detection. J. Antoni et al. [13] listed the rocking and twisting of the engine block on its supports due to the action of inertial forces" and the impacts due to clearances associated with the crankshaft and piston gudgeon pin bearings as other sources of vibration in engines. The obstacles posed by the source separation issue have led to a considerable number of investigations that focus on the development and application of source separation techniques. K. Jafarian et al. [1] Presented vibration analysis within the industry to detect and categorize faults that appeared thanks to valve clearance and incomplete combustion sometimes called the misfiring phenomenon within the combustion engine. They used four accelerometers on OHV engine body for registering vibration signals. And using PCA technique acquiring data was investigated. They succeeded to classify and detect faults with a high ratio of efficiency. S. Liu at al. [14] Proposed a technique for the detection of incipient engine valve faults by signals of vibration measured on the engine cylinder head. The characteristics of the vibration signal are analyzed, indicating that its time domain and frequency domain characteristics are both useful for engine diagnosis but a disadvantage of this method is the cycle-by-cycle variation. A simple diagnostic technique named partial sampling and feature averaging (PSFA) has been presented. A specific part of the vibration signal corresponding to a particular impact force within each operating cycle is sampled and analyzed, and then the diagnostic features are extracted from each part but averaged among many cycles. The experimental results show that the proposed technique is feasible, simple, and effective in implementation.

Vibration problems may originate from systems like the engine, pumps, drivetrain, wheels, and tires, or is also associated with system integration issues, as an example matching between powertrain and body and between chassis and body [15]. Vibration is one of the most common problems customers suffer from. Vibration may be caused by a problem with the engine, unbalanced tires and wheels, and brake vibrations. A series of diagnostic tests have to be conducted in order to identify the root cause of vibration. Humans feel vibrations and recognize it. Humans feel vibrations and recognize it. All vibration analysis was done by listening and feeling before any instruments became available. This method is still used by those who do not have access to instruments. Humans have some built-in sensors in our skin and our ears. These biological transducers served a survival function and still do. The human ear is amazingly sensitive to the smallest pressure change. Using the human ear for frequency analysis of vehicle noise is more effective when the ear can be coupled directly to the vehicle. Using the human ear for frequency analysis of vehicle noise is more effective when the ear can be coupled directly to the vehicle Human judgment of vibration severity can be quantified by the level of acceleration $0.001-0.01 \mathrm{~g}$ is the threshold of perception , $0.1 \mathrm{~g}$ is considered unpleasant and $0.5 \mathrm{~g}$ is considered intolerable by most subjects [16].

\section{IDD (IMMEDIATE DIAGNOSIS DEVICE)}

IDD is an immediate malfunction detection device using mechanical vibration analysis is designed and developed to reduce the time and effort expended by traditional steps in determining the source of the engine failure. A device is a separate unit that monitors the engine vibrations through the vibration sensor and the engine speed through the speed sensor. The device constantly compares the engine vibrations to the normal engine condition. In the event of a fault, the device displays a message on the display indicating the cause of the malfunction. It is able to diagnose faults of internal combustion engines.

\subsection{IDD Components}

Figure 4 shows the schematic drawing of IDD that consists of a power supply, primary board, mainboard and fuel cut off board. The primary board is used to convert 12 VDC battery voltage to 5 VDC. It receives vibration signals from a vibration sensor fixed on the engine body, amplifies the vibration signals and sends it to the mainboard. The mainboard stores, processes and compares the signals by using pre-programmed data, then views a message including the engine condition. 


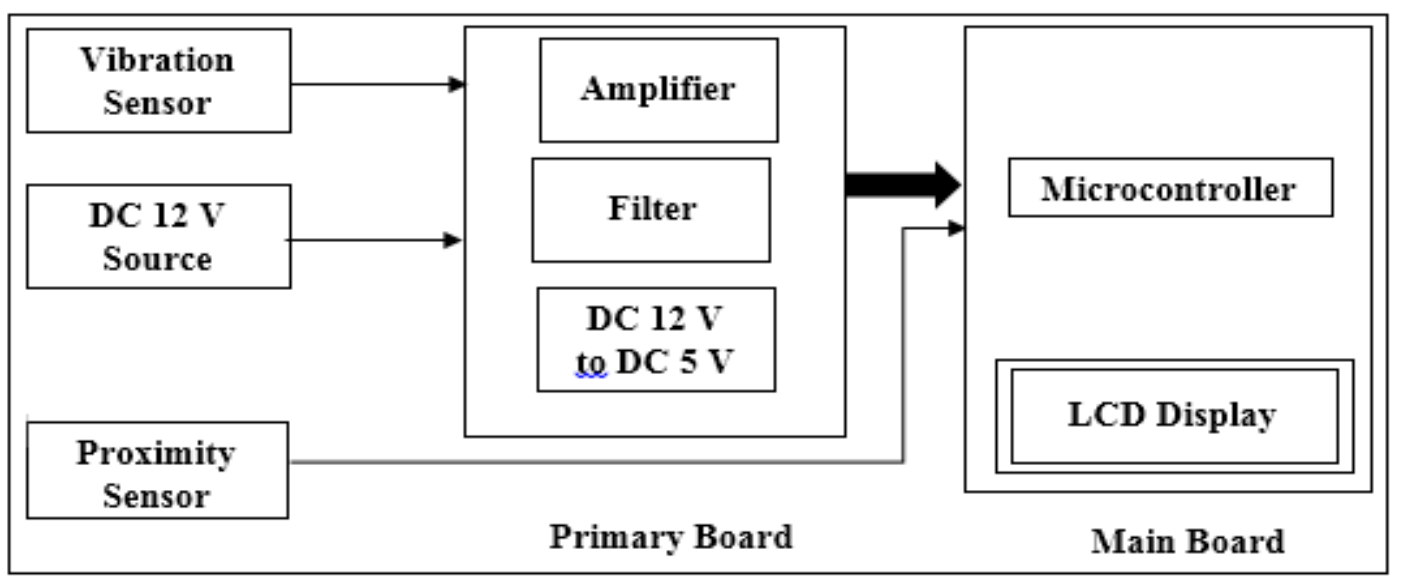

Figure 4: Schematic of IDD

Figure 5 Schematic drawing of the IDD operation flowchart which shows the sequence of the flow of the operations in the presented IDD. When pressed on the IDD diagnosis button, the IDD records vibration signals from a vibration sensor that is fixed on the engine body. Amplifies the vibration signals and sends them to the processing unit microcontroller to store and process them. Then compares it with the reference data. Finally, displays a message on the device screen LCD to explain the fault reason. The IDD continues to monitor the engine vibration, speed and repeats the diagnosis process until the start button is pressed again or the engine stops.

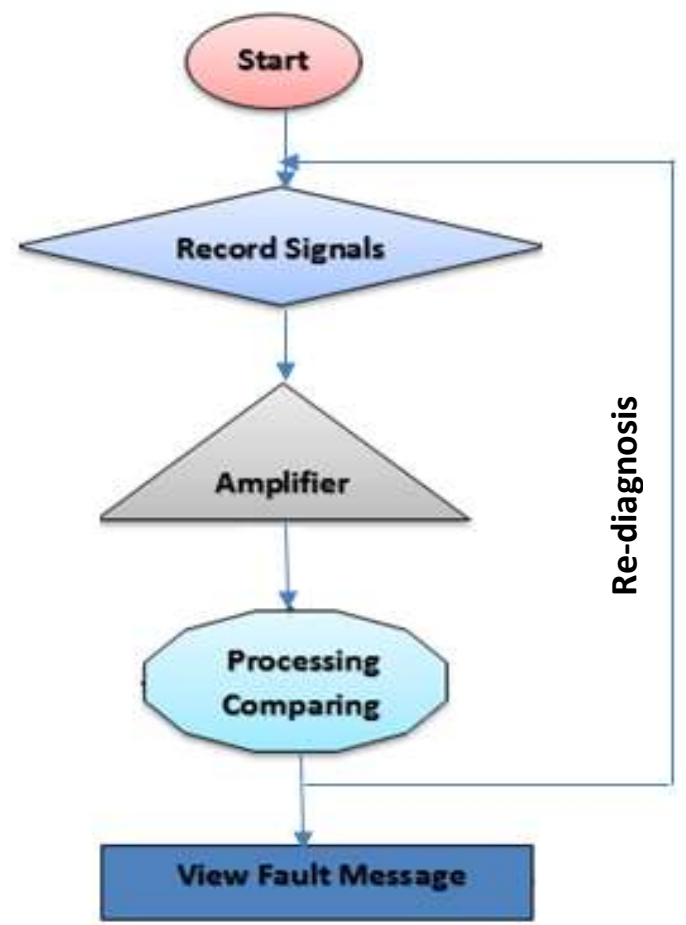

Figure 5: IDD Operation Flowchart

\subsection{IDD Design}

IDD is Consists of a primary board and mainboard. A primary board is consisting of a DC converter, filter and amplification unit. ADC converter converts a 12-volt vehicle battery voltage to 5 volt to operate the components of the device and vibration sensor. It has 4 regulators LM2575 and 4 dual operational amplifiers TLO72. a primary board is used for provides the voltage and electric current required to operate the vibration sensor, receiving, amplifying and sending vibration signals to the processor in the mainboard. Figure 6 shows photography of the primary board. 


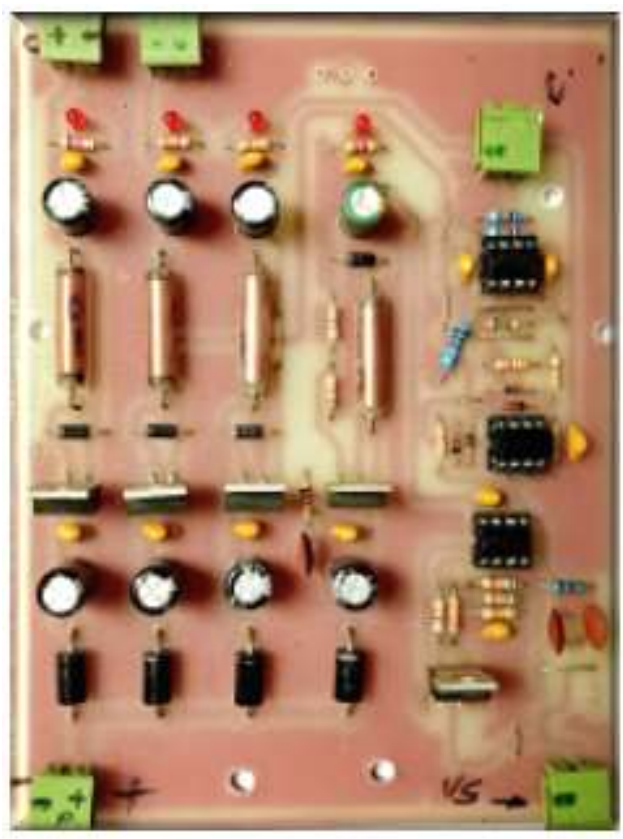

Figure 6: Primary board

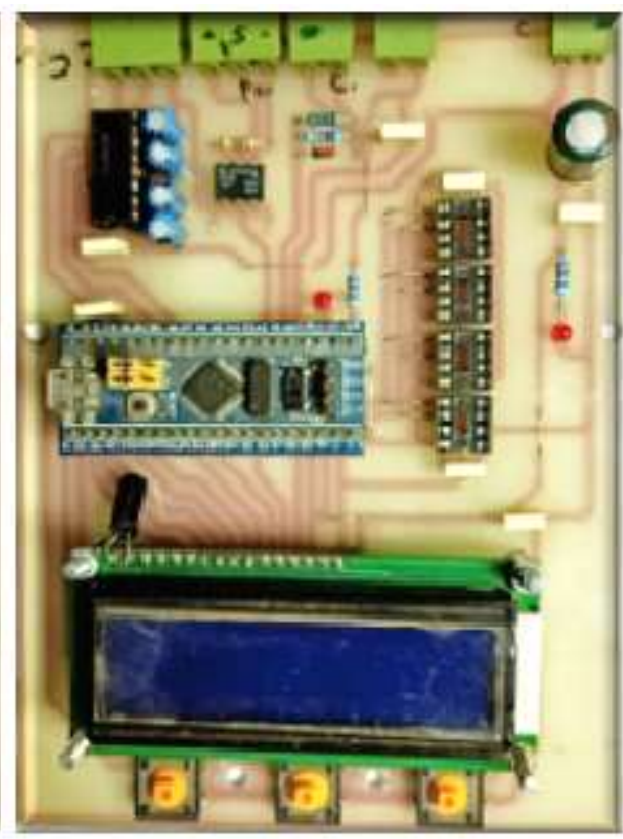

Figure 7: Mainboard

A main board consists of microcontroller 32BIT, LCD 8BIT, proximity sensor, LCD and power regulator. A main board is used to receive the samples from the primary board at specific conditions (constant rate samples- the engine rotation speed). It's able to connect with the computer for monitoring, programming, processing data, and views the results on the LCD. Figure 7 shows photography of a mainboard.

\subsection{IDD Software}

Using Microsoft visual studio and $\mathrm{C}++$ language, the program was designed to control and operate the IDD. It consists of several menus as shown in figure 8, the most important are file and tools. File menu containing the commands to start, save, open previous files and perform a comparison. Tools menu has option, detect speed and send delay. Option command used to set the device reference values to judge the validity of the signals and type fault codes as shown in figure 9 . This program goes through three stages of operations in order: recording, programing, and viewing the faults. After receiving the signal from the device, the program divides it into four parts. Then it calculates the RMS of the signals. The results are viewed in the time domain chart as a single signal and divided into four parts. This program can detect the speed of the experimental engine during experiments. Figure 11 shows the IDD Programming Steps.

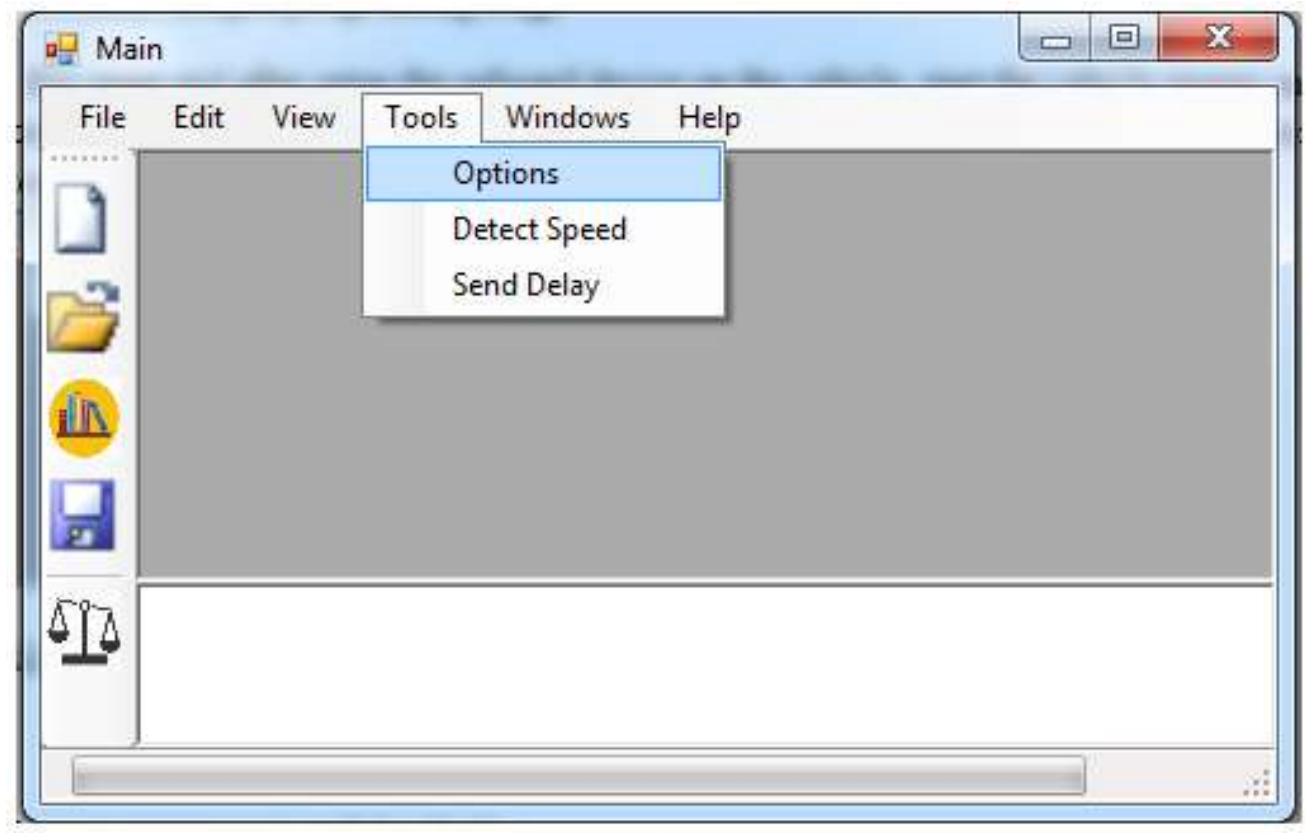

Figure 8: IDD Program Interface 


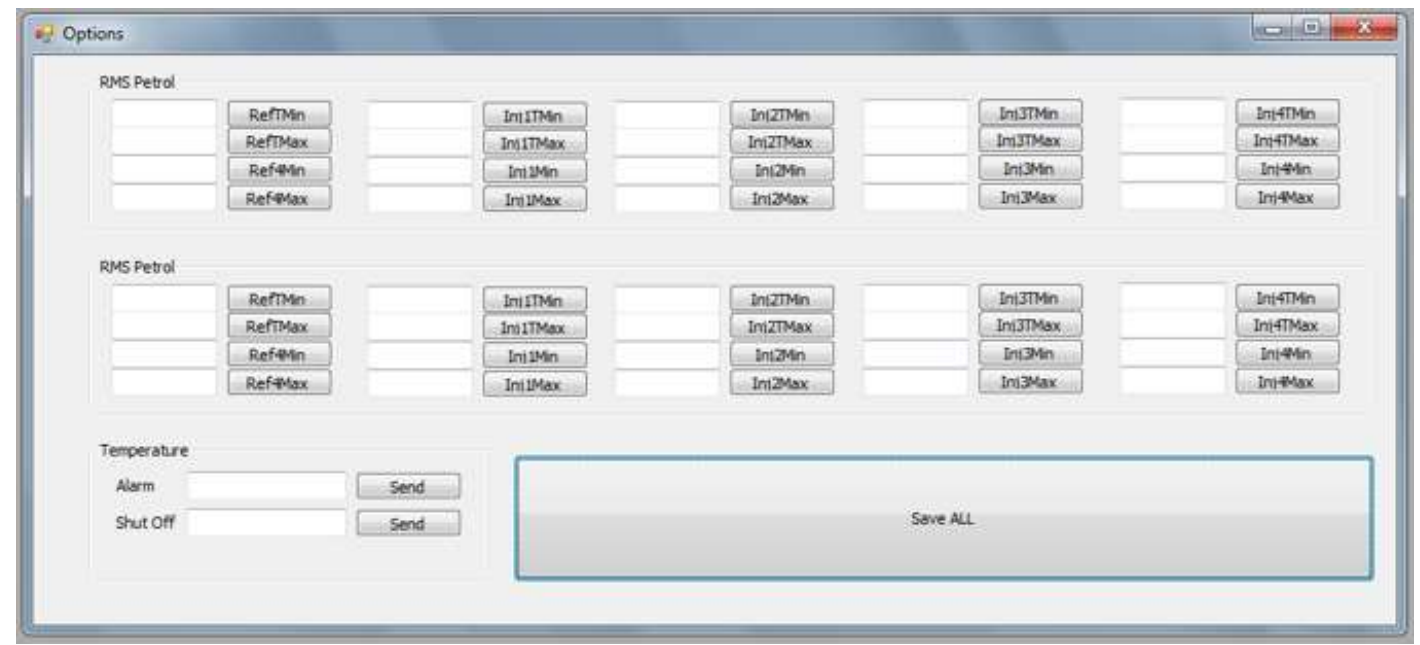

Figure 10: IDD Programming Interface

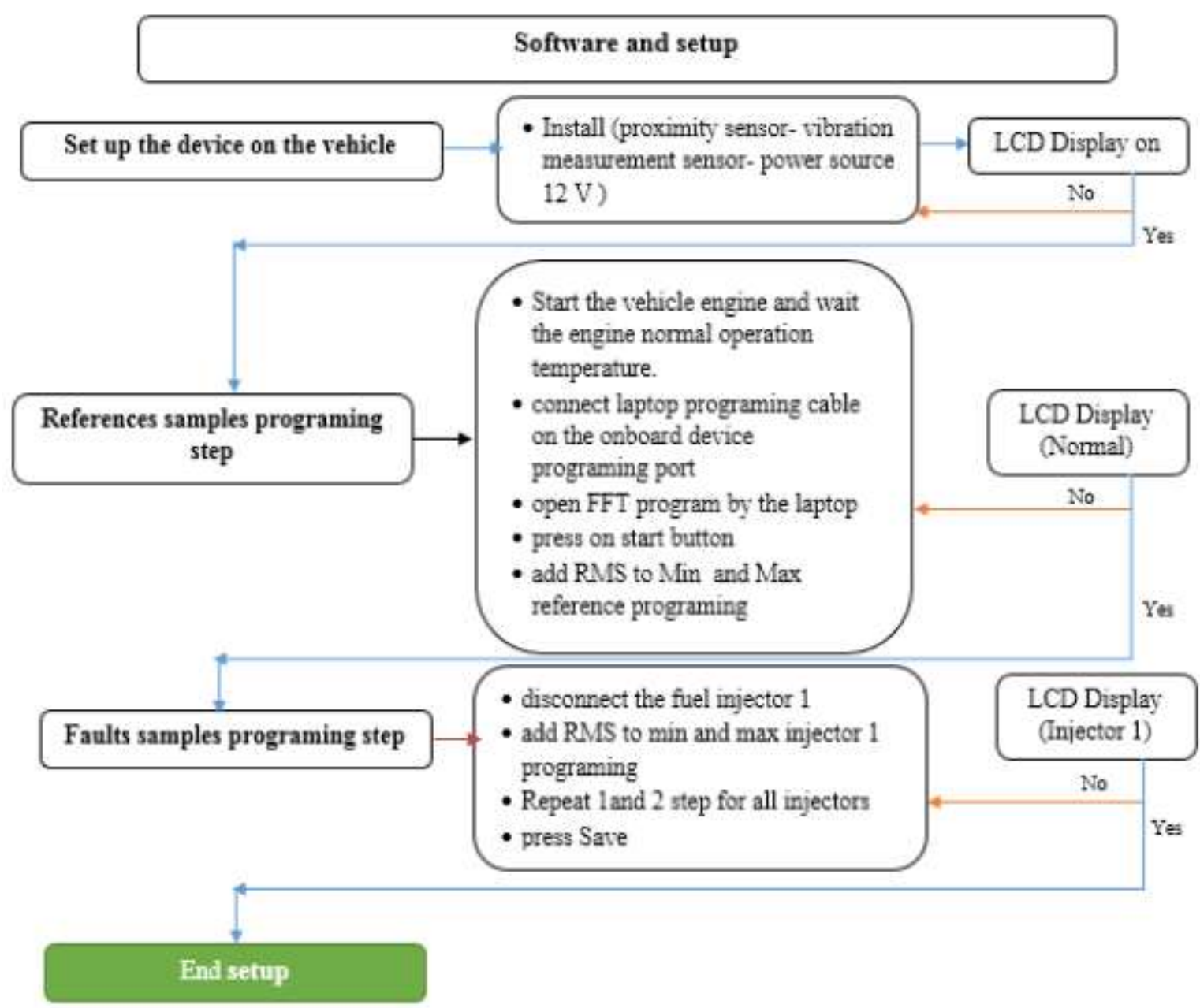

Figure 11: IDD Programming Steps

\section{RESULTS}

A new device was used to detect faults of a gasoline engine at $900 \mathrm{rpm}$ and $1500 \mathrm{rpm}$, for Daewoo Lanos, four-cylinders, $1500 \mathrm{cc}$, and single overhead camshaft. Firing order for each cylinder occurs consistent with 1-3-4-2. Figures from (12 to 21$)$ shows the vibration signal of Daewoo Lanos at normal conditions and ignition system fault with engine speed $900 \mathrm{rpm}$ and $1500 \mathrm{rpm}$. 
International Journal of Advances in Scientific Research and Engineering (ijasre), Vol 7 (10), October -2021

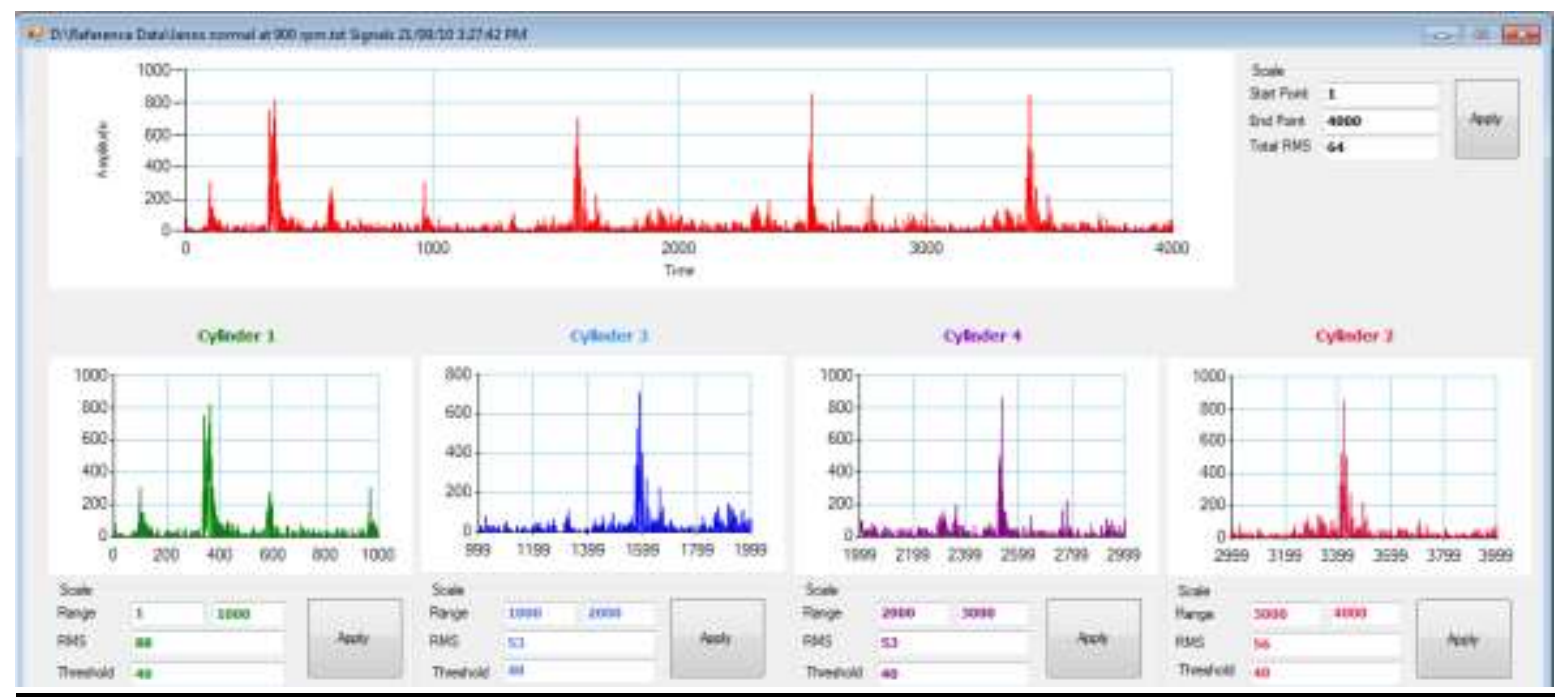

Figure 12: the IDD program at normal engine operation with 900 rpm.

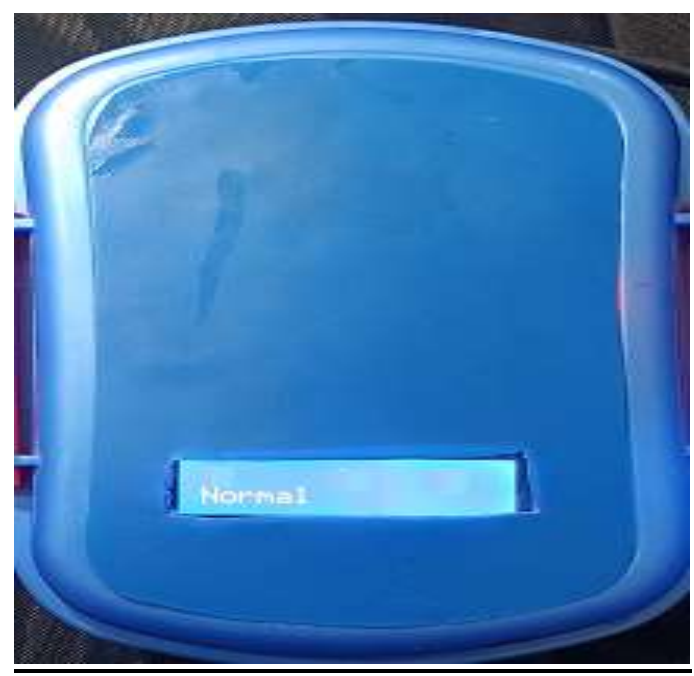

Figure 13: the IDD at normal engine operation with 900 rpm.

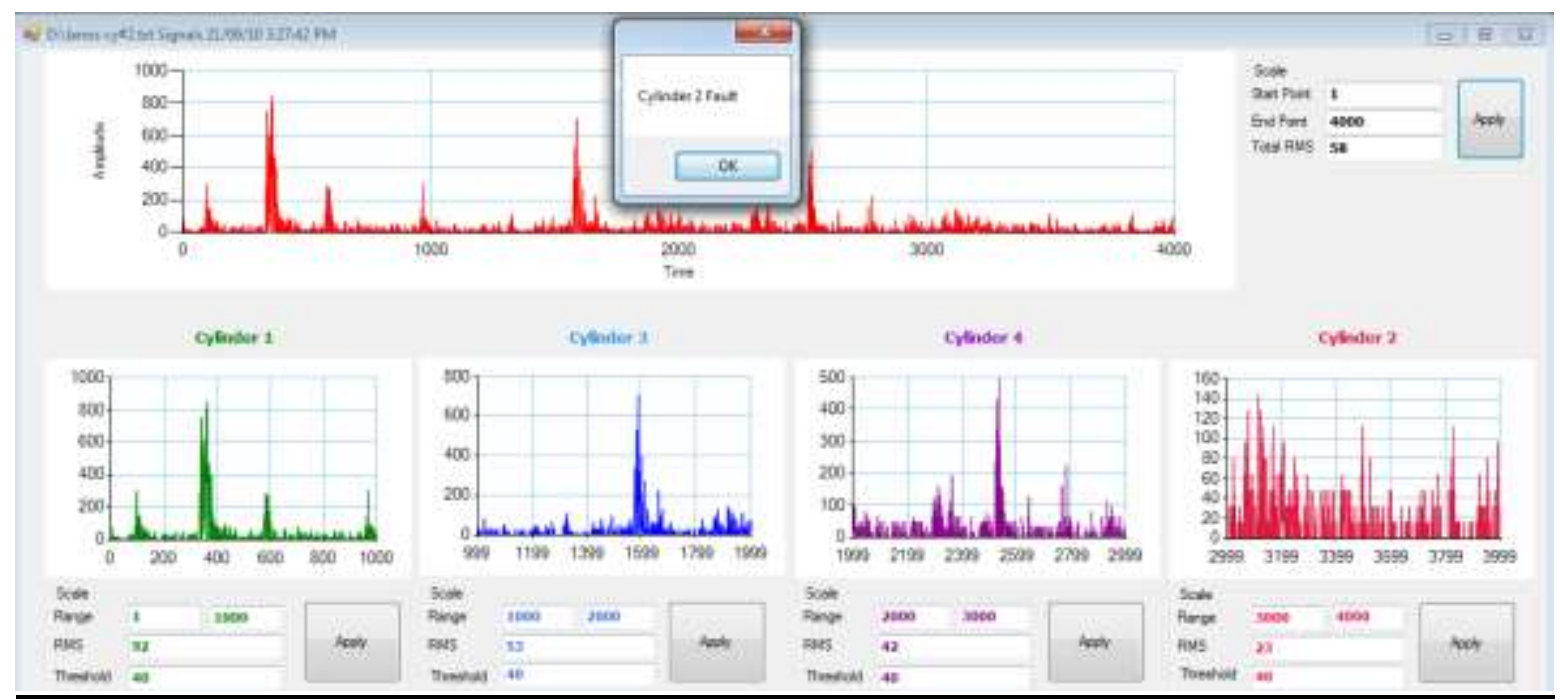

Figure 14: IDD program no ignition cylinder No. 2 with 900 rpm. 


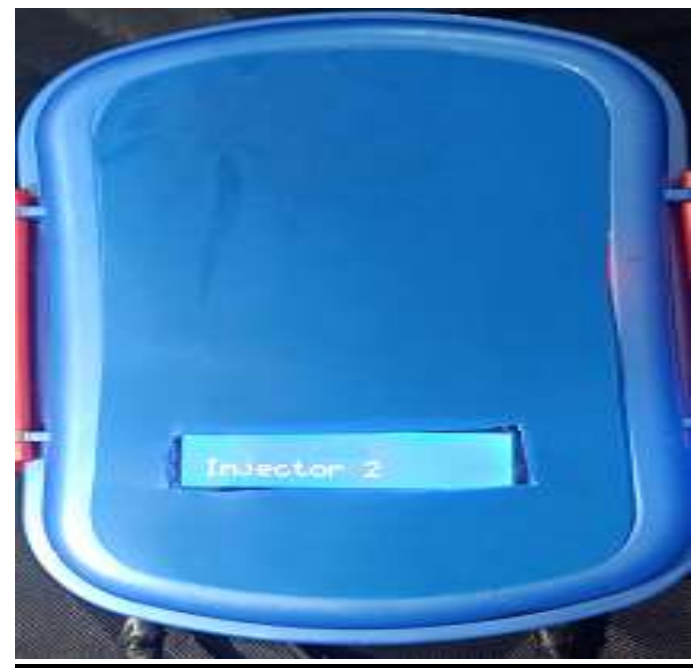

Figure 15: IDD no ignition cylinder No. 2 with 900 rpm.

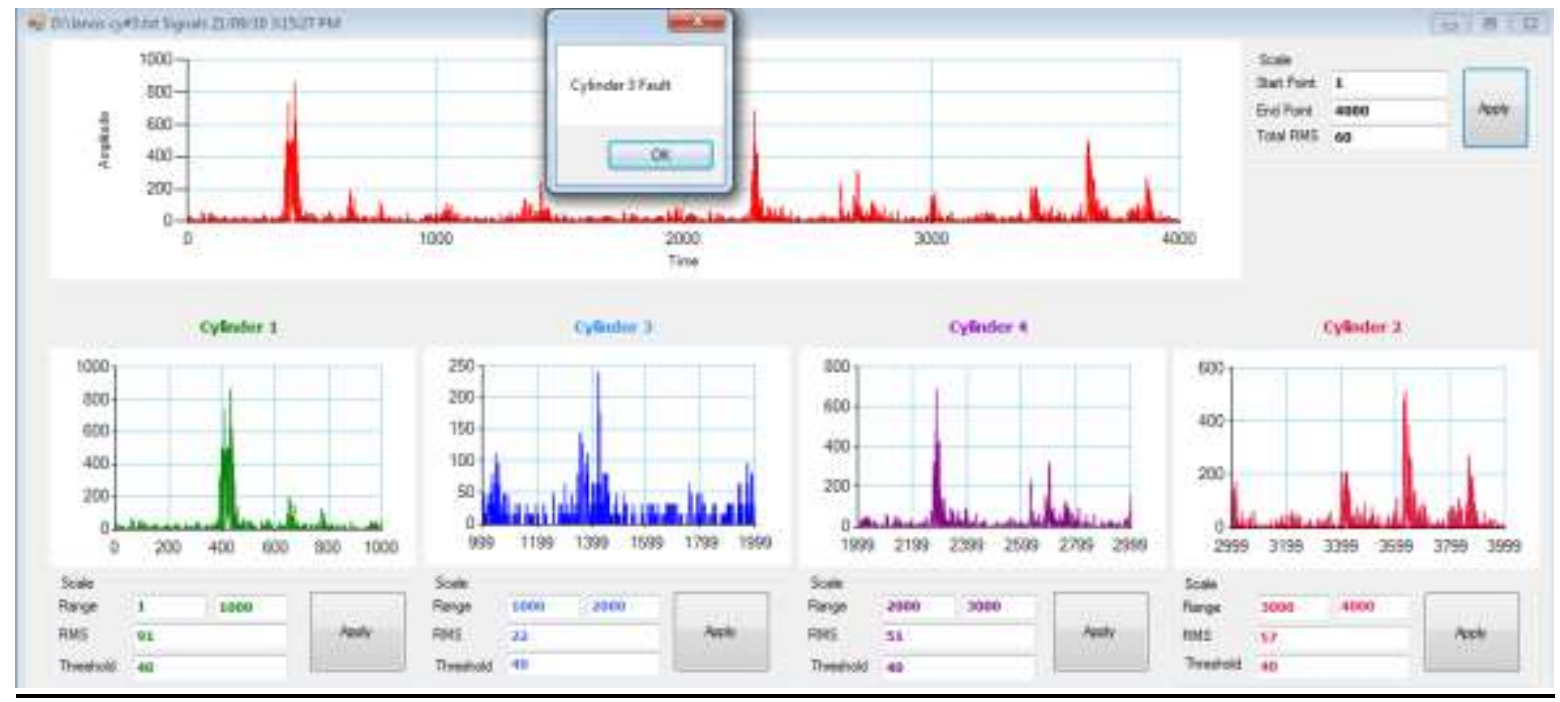

Figure 16: IDD no ignition program at cylinder No. 3 with 900 rpm.

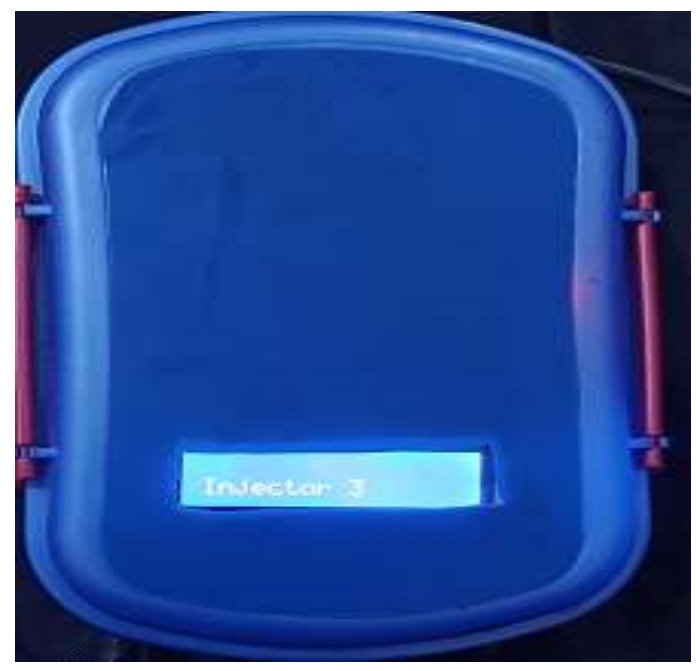

Figure 17: the IDD no ignition cylinder No. 3 with 900 rpm. 
International Journal of Advances in Scientific Research and Engineering (ijasre), Vol 7 (10), October -2021

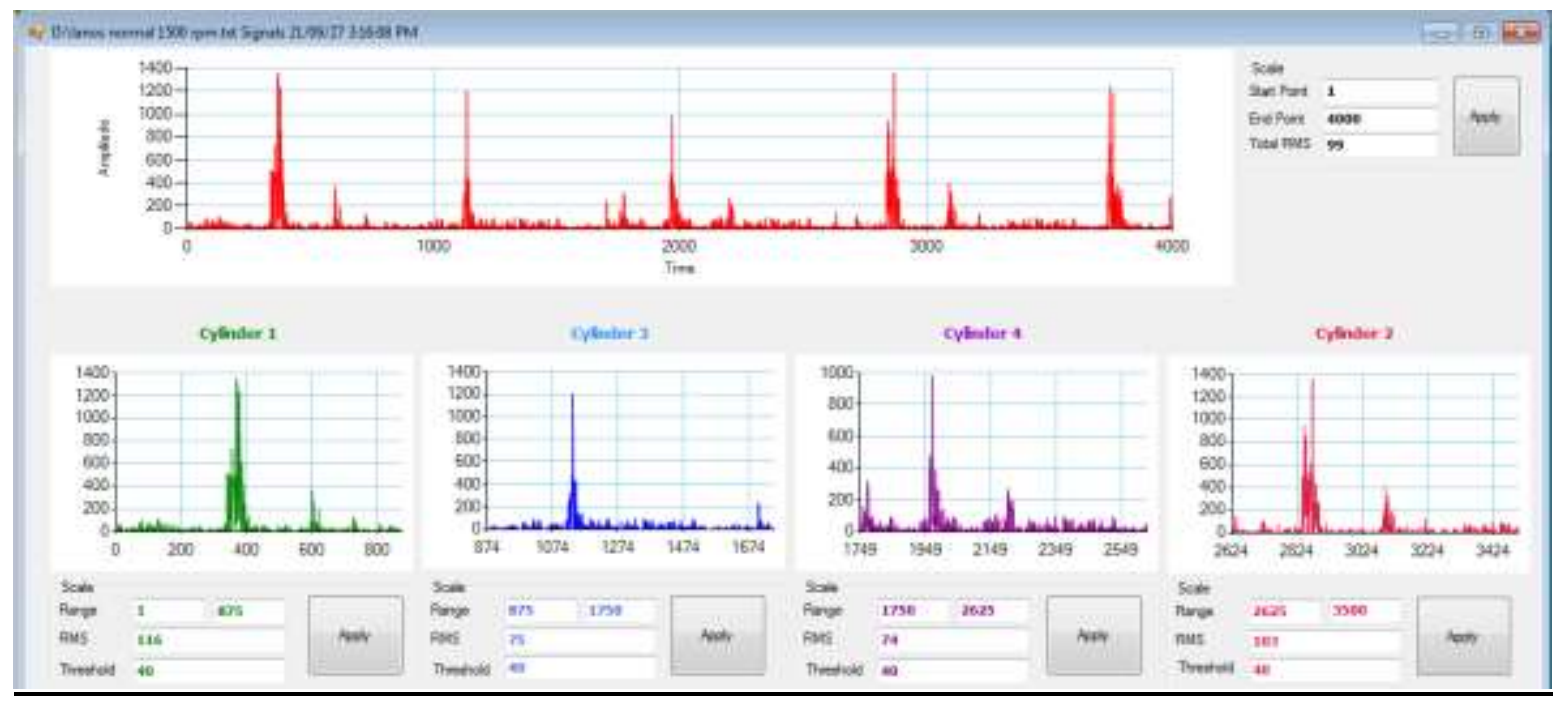

Figure 18: the IDD program at normal engine operation with $1500 \mathrm{rpm}$.

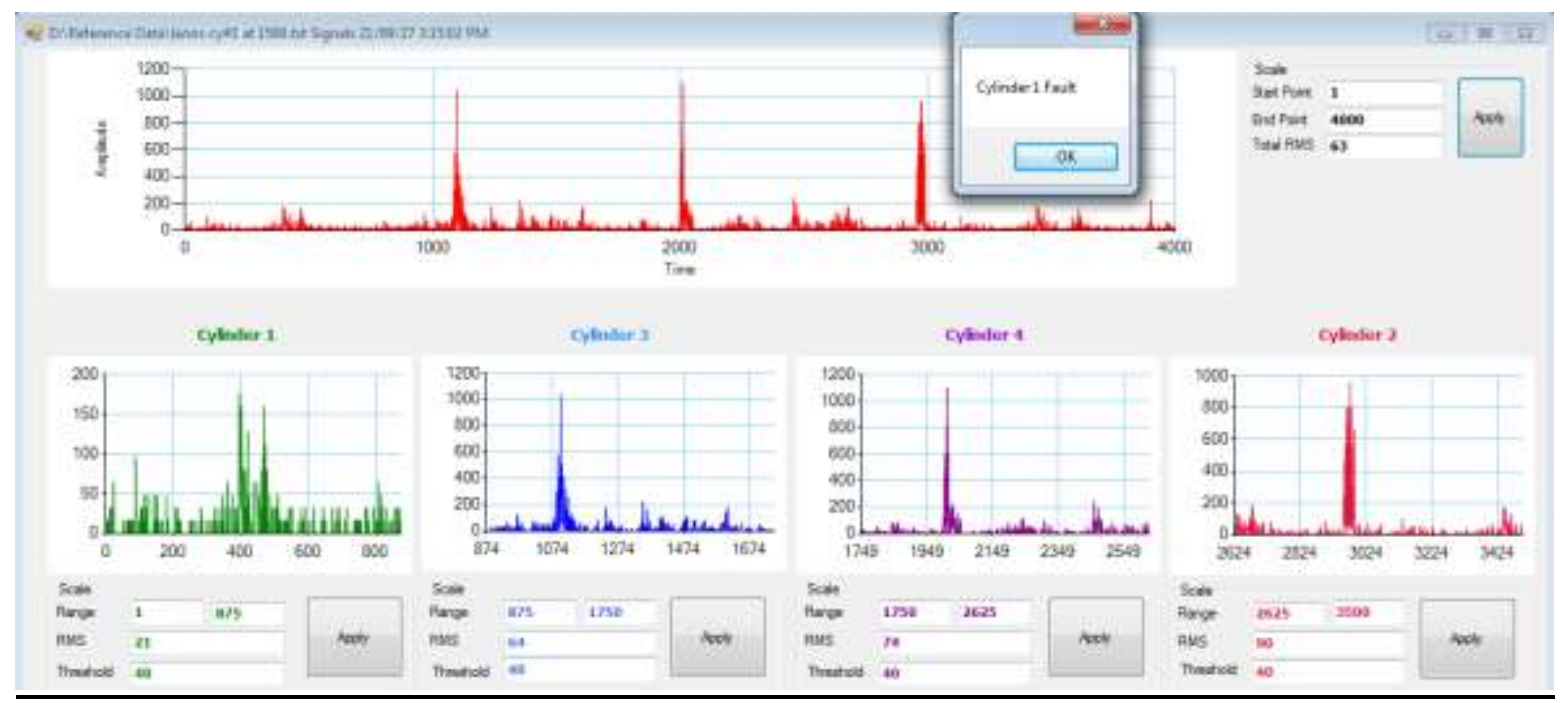

Figure 19: the IDD program no ignition cylinder No. 1 with 1500 rpm.

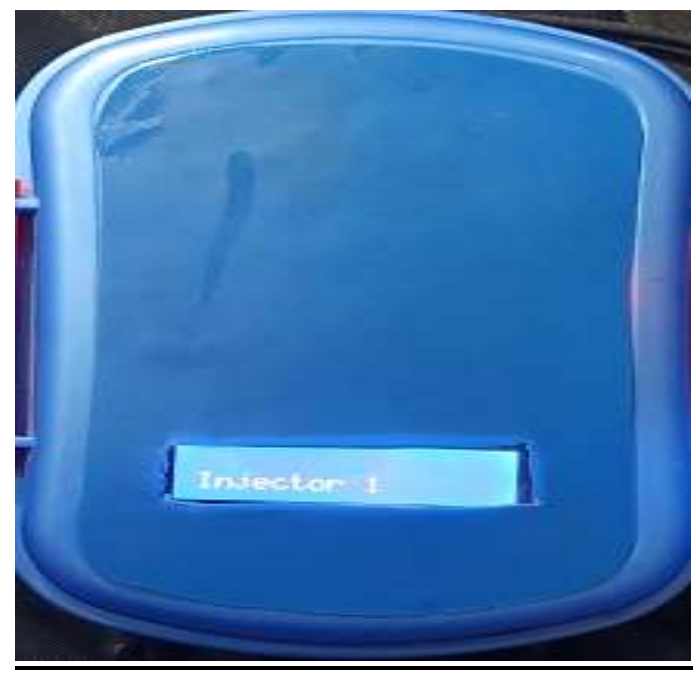

Figure 20: IDD no ignition cylinder No. 1 with 1500 rpm. 


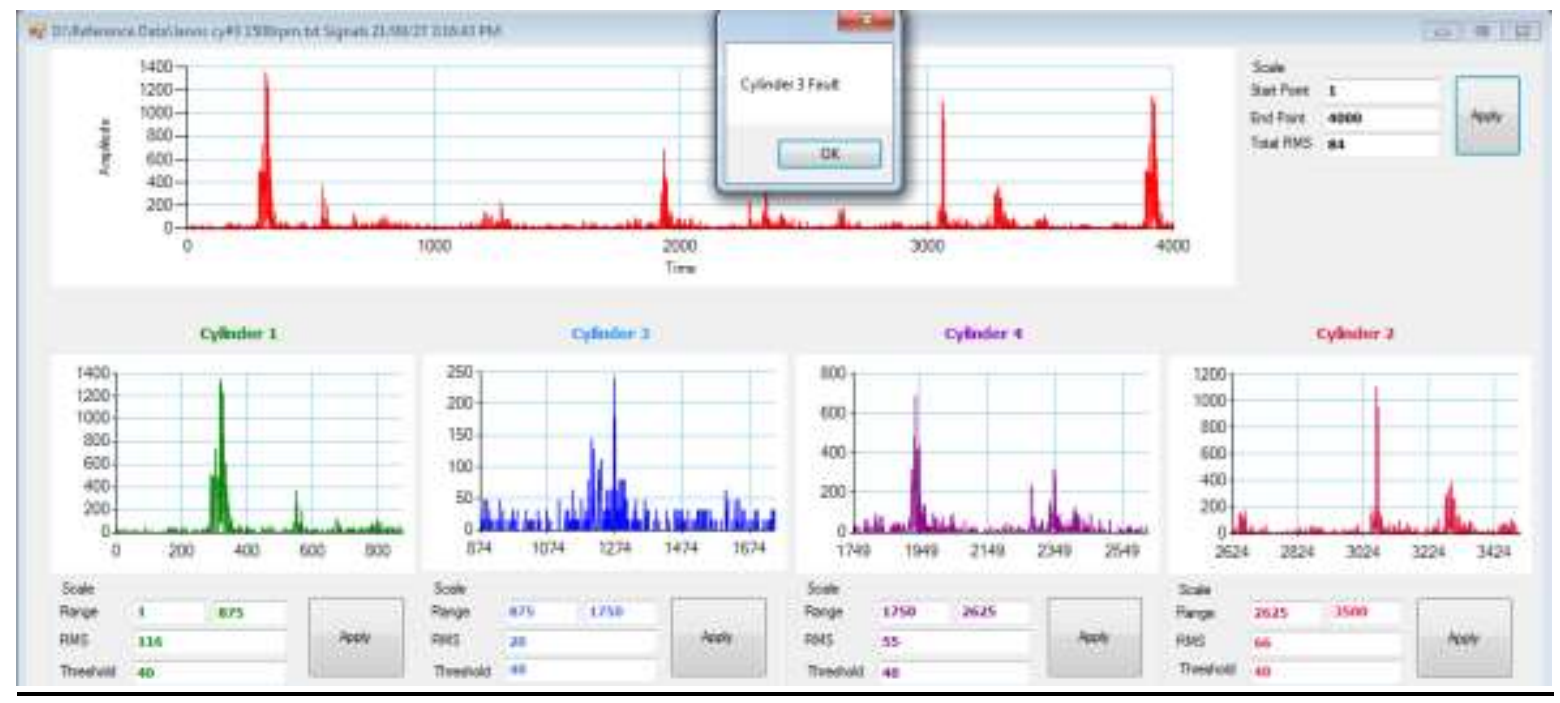

Figure 21: the IDD program, no ignition cylinder No. 3, with 1500 rpm.

\section{CONCLUSION}

IDD is a new invented device by the same authors, designed to save time and effort in detecting faults in the internal combustion engines by using mechanical vibration analysis and comparison of normal and faults. It easy to use in time domain to detect faults. A series of faults were carried out on the ignition system to assess the ability of IDD to vibration signal analysis and detect these faults through the comparison of the health system with the fault such as disconnect spark plug wire. The quality of vibration signals in vehicles is affected due to the presence of various interferences while the car is running. The device proved effective in vehicles fault detection and it can be safely used in different similar applications such as; pumps, compressors, turbines, electric motors and washing machines.

\section{REFERENCES}

[1] K.Jafarian,M.Darjani and Z.Honarkar, Vibration Analysis for Fault Detection of Automobile Engine Using PCA Technique, Qazvin Islamic Azad University, Qazvin, Iran: International Conference on Control, Instrumentation, and Automation (ICCIA), 2016.

[2] K. Elbhbah and J. K. Sinha, "Vibration-based condition monitoring of rotating machines using a machine composite spectrum," 2013.

[3] S. Allam, M .Abdo and M. Rabie, "Diesel Engine Fault Detection Using Vibration and Acoustic Emission Signals," International Journal of Advances in Scientific Research and Engineering (ijasre) , vol. 4, no. 12, p. 86, 2018. DOI: https://doi.org/10.31695/IJASRE.2018.33005

[4] S.You, M.Krage and L.Jalics, Overview of Remote Diagnosis and Maintenance for Automotive Systems, USA: SAE International, 2005.

[5] D. Watzenig, M. S. Sommer and G. Steiner, Engine state monitoring and fault diagnosis of large marine diesel engines, Springer, 2009.

[6] S. Allam, M. Abdo and M. khairy, "A survey of Internal Combustion Engine Condition Monitoring and Fault Detection Techniques," International Journal of Advances in Scientific Research and Engineering (ijasre), vol. 12, no. 2454-8006, p. 6, 2020. DOI: https://doi.org/10.31695/IJASRE.2020.33950

[7] Claudio, A. H, Multi-sensor Approach to the Diagnostics of Reciprocating Compressor, PhD, thesis University of Arkansas at Little Rock, 1994. 
[8] S.Allam, M.Abdo and M. Rabie, "Experimental Assessment of Diesel Fuel Injection System Faults Using Vibration Signal Analysis," International Journal of Advances in Scientific Research and Engineering (ijasre), vol. 5, no. 2454-8006, 2019. DOI: https://doi.org/10.31695/IJASRE.2019.33197

[9] D.P.Lowe, Characterisation of Combustion Related Acoustic Emission Sources for Diesel Engine Condition Monitoring, Doctor of Philosophy thesis, May 2013.

[10] F.A.Shirazi, M.Ayati, A.Z.Hesari and S. A.Rad, "Fuel Injection Fault Detection in a Diesel Engine Based on Vibration Signature Analysis," Iranian International NDT Conference, pp. 4-5, 2018.

[11] Z.Geng and J.Chen, "Investigation into piston-slap-induced vibration for engine condition simulation and monitoring," Journal of Sound and Vibration, vol. 282, no. 3-5, pp. 735-751, 2005.

[12] A. Zabihi, S. Ansari, F. Shirazi and M.Ayati, "Fault detection and diagnosis of a 12-cylinder trainset diesel engine basedon vibration signature analysis andneural network," Mechanical Engineering Science, p. 1-14, 2018.

[13] J. Antoni, J. Daniere, and F. Guillet, "Effective Vibration analysis of IC Engines Using Cyclostationarity," Methodology for Condition Monitoring. Journal of Sound and Vibration, no. 815-837, p. 257, 2002.

[14] S. Liu, F. Gu, and A .Ball, Detection of engine valve faults by vibration signals measured on the cylinder head, Manchester, UK: JAUTO90, 2006.

[15] Xu Wang, Vehicle noise and vibration refinement, Cambridge CB21 6AH, UK: Woodhead Publishing Limited, 2010.

[16] X. WANG, Vehicle vibration measurement and analysis, RMIT University, Australia, 2010. 